\title{
Feasibility Study on Listing of Pharmaceutical Enterprises Based on Financial Analysis: Take Company Y as an Example
}

\author{
Yan Ma \\ Faculty of Accounting, Anhui University of Finance and Economics, Bengbu, China \\ Email: YanMa@163.com
}

How to cite this paper: Ma, Y. (2021). Feasibility Study on Listing of Pharmaceutical Enterprises Based on Financial Analysis: Take Company Y as an Example. Open Journal of Business and Management, 9, 1325-1337.

https://doi.org/10.4236/ojbm.2021.93072

Received: March 15, 2021

Accepted: May 28, 2021

Published: May 31, 2021

Copyright $\odot 2021$ by author(s) and Scientific Research Publishing Inc. This work is licensed under the Creative Commons Attribution International License (CC BY 4.0).

http://creativecommons.org/licenses/by/4.0/

\begin{abstract}
Health has always been one of people's demands for a high quality of life. For thousands of years, both Chinese and Western medicine have accumulated a lot of medical knowledge and ideas. However, due to the weakness of China in the past century, Chinese medicine has become irrelevant. However, with the outbreak and persistence of COVID-19 and China's actions in the fight against the epidemic, people have further realized the importance of health, and TCM has again entered people's field of vision. Taking Company Y as an example, this paper analyzes the listing feasibility of Company $\mathrm{Y}$ from its macro environment, basic overview, advantages and disadvantages in the industry, financial indicators, enterprise valuation and other aspects. Then, based on the above analysis and combined with the development trend and recent development goals of the enterprise, it concludes that under the current macro and micro environment, Company $\mathrm{Y}$ can and should be encouraged to list on the New Third Board, with a stock price of about 7 yuan and a price-earnings ratio of about 25 times.
\end{abstract}

\section{Keywords}

Chinese Medicine Industry, Y Company, Listing Valuation, Financial Analysis

\section{Introduction}

In recent years, TCM, as a unique resource in China, has played an increasingly important role in China's economic and social development. In order to meet the people's demand for TCM services and give full play to the unique role of TCM in social development, the State Council issued the Outline of the Strategic Plan for the Development of TCM (2016-2030) in February 2016, which aims to 
achieve full coverage of TCM services by 2030 and take the TCM industry to a new level. In the same year, to further improve the TCM service system, the Conference adopted the Pharmaceutical Law of the People's Republic of China, which came into effect on July 1, 2017. A series of policies for traditional Chinese medicine industry to build a good environment for development, to the traditional Chinese medicine industry in our country have created a new space to grow up.

\section{Analysis of the Macro Environment}

\subsection{Political and Legal Environment}

With the gradual deepening and improvement of the reform of the national medical system, new medical policies will be gradually implemented to accelerate the standardization and standardization of my country's pharmaceutical industry. The competition in China's pharmaceutical industry is undergoing new changes, which may affect the production and operation of state-owned enterprises within a certain period of time. The specific policy content is shown in Table 1.

\subsection{Economic Environment}

The advancement of science and technology continues, and China's medical expenses are still far lower than those of developed countries. In 2018, my country's traditional Chinese medicine processing and manufacturing industry had an operating income of 239.5 billion yuan and a total profit of 16.5 billion yuan (Data source: Compiled by China Commercial Industry Research Institute). As shown in Figure 1, from 2011 to 2020, China's medical expenditures have shown a steady upward trend. As one of the three pillar industries of the traditional Chinese medicine industry, the traditional Chinese medicine decoction pieces industry has become the fastest growing sub-industry in the pharmaceutical industry in the past decade.

\subsection{Social and Cultural Environment}

In recent years, the number of outpatient visits in TCM medical institutions has increased, reaching approximately 1 billion visits by 2017. The cost of medicines for inpatients in integrated Chinese and Western hospitals has also increased year by year, and the number of discharged patients from Chinese-type medical institutions has increased significantly. By making full use of the unique advantages of traditional Chinese medicine, we will continue to promote the traditional Chinese medicine service system to the grassroots level, so that it can play an important role in the treatment of disease, treatment and rehabilitation of major diseases. Our country has further deepened reforms, improved the development of Chinese medicine at the local level, and continued to modernize Chinese medicine. Speeding up the pace of "going out" has created a new form for the 
Table 1. Specific policies and content.

\begin{tabular}{lll}
\hline time policy & main content \\
\hline 2015.4 "Plan for the Protection and & Comprehensive arrangements have been made for the protection of Chinese herbal medicine \\
Development of Chinese Medicinal & $\begin{array}{l}\text { resources and the development of the Chinese herbal medicine industry for the current and } \\
\text { Materials (2015-2020)" }\end{array}$ & $\begin{array}{l}\text { future periods. This is my country's first national-level plan for the protection and } \\
\text { development of Chinese herbal medicines. }\end{array}$
\end{tabular}

2016.2 "Outline of the Strategic Plan for the

By 2020, everyone will basically have access to traditional Chinese medicine services. The Development of Traditional Chinese Medicine (2016-2030)"

fields of traditional Chinese medicine medical treatment, health care, scientific research, education, and industrial culture will be comprehensively developed in a coordinated manner. The standardization, informatization, industrialization, and modernization of traditional Chinese medicine will continue to improve.

2017.1 “The Belt and Road Development Plan of It is clarified that by 2020, a new pattern of all-round cooperation on the "Belt and Road" of Traditional Chinese Medicine (2016-2020)" traditional Chinese medicine will be basically formed. 30 overseas Chinese medicine centers will be established with countries along the route, 20 international standards for traditional Chinese medicine will be promulgated, 100 traditional Chinese medicine products will be registered, and 50 traditional Chinese medicine bases will be built.

2018.1 "Guidelines for Supervision of The policy pointed out that the "Guide" should be further revised and improved, which will Traditional Chinese Medicine (Beta)" lay a good foundation for the implementation of the "Guide" nationwide in the future. Accelerate the development of supervision and law enforcement of traditional Chinese medicine, clarify the duties and tasks of supervision and law enforcement of traditional Chinese medicine, establish and improve the work system, and enhance the ability of supervision and law enforcement. Improve the basic theory of Chinese medicine supervision and law enforcement, strengthen the standardized construction of Chinese medicine supervision and law enforcement, and play a role of demonstration and guidance.

2018.4 "Announcement on the Technical In order to strengthen the management of traditional Chinese medicine decoction pieces, Guiding Principles for the Revision of the standardize the revision of provincial-level Chinese medicine decoction pieces processing Processing Standards of Chinese Herbal norms, and enhance the controllability of the quality of traditional Chinese medicine Medicine at the Provincial Level (No. 16 decoction pieces, the National Medical Products Administration organized and formulated the of 2018)

"Provincial-level TCM Decoction Pieces Processing Norms Revision Technical Guidelines."

2018.7 "Management Standards for the In order to regulate the production of Chinese medicinal materials, ensure the quality of Production Quality of Chinese Medicinal Chinese medicinal materials, and promote the standardization and standardization of Chinese Materials (Draft for Solicitation of Comments)" medicinal materials production, enterprises shall organize the production of Chinese medicinal materials in strict accordance with the requirements of this specification, protect wild Chinese medicinal materials and the ecological environment, and promote the sustainable use and development of Chinese medicinal materials resources.

2018.8 "Guiding Opinions on Strengthening the By 2030, establish a TCM health service technology innovation system centered on the full life Innovation of Traditional Chinese Medicine Health Services" cycle health service chain of preventive health care, medical treatment, and rehabilitation, improve the "production, study, research and medical" collaborative innovation mechanism, and significantly improve the technological innovation capabilities of TCM health services. It is necessary to take traditional Chinese medicine as the main body, integrate the technical methods of modern medicine and other disciplines, continuously improve the theoretical knowledge of traditional Chinese medicine health services, develop traditional Chinese medicine health service technologies and methods, enrich traditional Chinese medicine health service products, and innovate traditional Chinese medicine health service models.

2018.12 "Plan for the Construction of National Authentic Medicinal Materials Production Base (2018-2025)"

By 2020, a standardized production system for authentic medicinal materials will be established, and a system for protecting and monitoring authentic medicinal materials resources will be basically completed: Accelerate the construction of production bases covering key production areas of authentic medicinal materials. By 2025, complete the protection and monitoring system of authentic medicinal materials, establish a complete production and circulation system for authentic medicinal materials, build a standardized production base covering the main authentic medicinal materials, and comprehensively strengthen the management of authentic medicinal materials, the coverage rate of good varieties will reach more than $50 \%$ and green prevention and control achieve full coverage. 


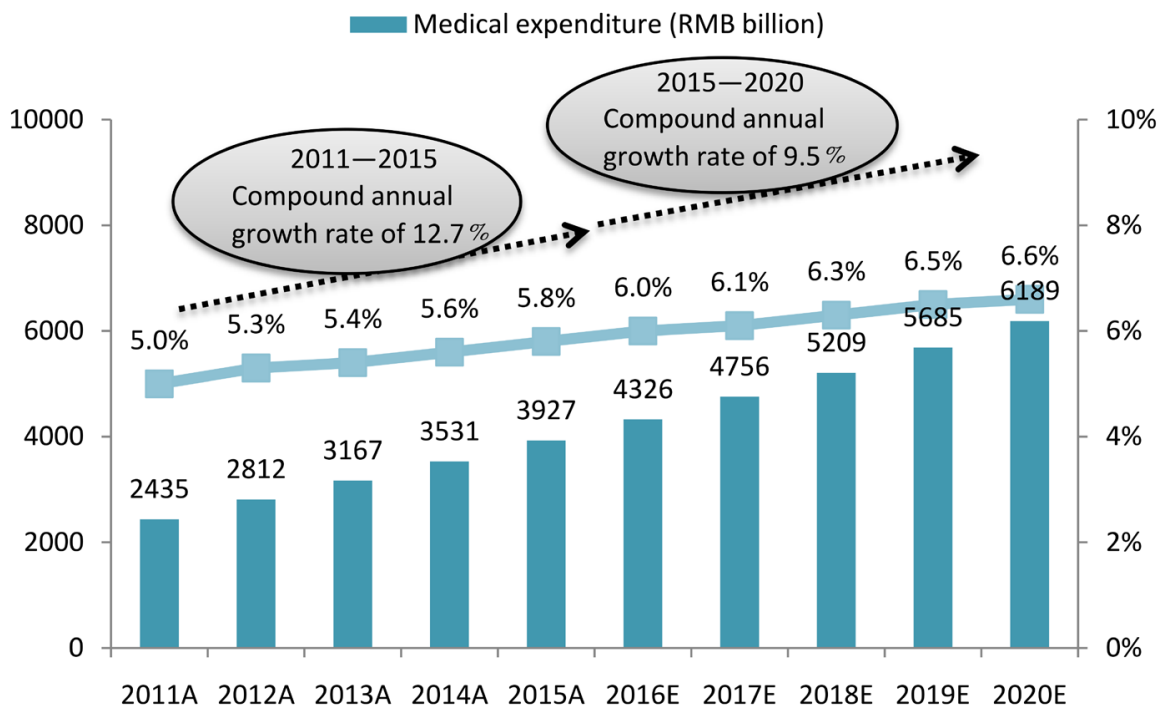

Figure 1. China's medical expenses.

revitalization and development of Chinese medicine.

\subsection{Technical Environment}

With the development and progress of science and technology, the development of the field of "wisdom + Chinese herbal medicine" has diversified. The main forms are online consultation, Chinese herbal medicine e-commerce, $\mathrm{O} 2 \mathrm{O}$ medicine delivery, $\mathrm{O} 2 \mathrm{O}$ massage and health care and Chinese medicine education, Chinese medicine media, health management and intelligent equipment through the Internet. In the future, with the rapid development of 5G, artificial intelligence and other technologies, the Chinese medicine industry will also develop rapidly.

\section{Basic Business Information of Company $Y$}

Based on the processing of TCM decoction pieces, Y Company has formed a complete industrial chain from the planting of medicinal materials, to the processing of TCM decoction pieces, and finally to product sales. Company constantly improve the product marketing system, its point-of-sale realizing a complete coverage of the country, are steadily expand foreign markets at the same time, and get widely recognized at home and abroad customers. The company has a good development prospect. Y Company adheres to encouraging independent innovation and creating a good innovation environment for employees. Since its establishment, Y Company has owned 12 patents, and another 14 patents have entered the substantive review stage, making continuous progress in technological innovation.

It can be seen from Table 2 that the sales revenue of ordinary Chinese medicine decoction pieces accounted for more than $90 \%$ of the main business revenue in the past three years, and was as high as $99.38 \%$ in 2016 , showing a downward 
Table 2. Composition of Main Business Income from 2016 to 2018.

\begin{tabular}{ccccccc} 
& \multicolumn{2}{c}{2016} & \multicolumn{2}{c}{2017} & \multicolumn{2}{c}{ Unit: 10,000 Yuan } \\
\hline \multirow{2}{*}{ The product name } & amount & $\begin{array}{c}\text { Percentage } \\
(\%)\end{array}$ & amount & $\begin{array}{c}\text { Percentage } \\
(\%)\end{array}$ & amount & $\begin{array}{c}\text { Percentage } \\
(\%)\end{array}$ \\
\cline { 2 - 7 } & & 99.38 & $28,161.57$ & 99.32 & $12,053.06$ & 98.65 \\
Ordinary yinpian & $24,044.18$ & 0.62 & 167.74 & 0.59 & 25.12 & 0.21 \\
The toxicity of yinpian & 150.29 & - & 25.23 & 0.09 & 139.29 & 1.14 \\
Direct oral yinpian & - & - & 100 & $12,217.47$ & 100 \\
\hline Sum up & $24,194.47$ & 100.00 & $28,354.53$ & 100 &
\end{tabular}

trend in recent years. Secondly, with the development of traditional Chinese medicine industry, the sales revenue of direct oral decoction pieces has increased, and people are in pursuit of more convenient traditional Chinese medicine products. Therefore, the company has been constantly improving and innovating in accordance with the social demand.

\section{Advantages and Disadvantages of the Companies to Be Listed in the Industry (SWOT Analysis)}

\subsection{Strengths}

- Advantages of raw materials: The headquarter of the company is located in Bozhou, Anhui Province, "the capital of Chinese medicine and hometown of Huatuo". It is famous at home and abroad for its long civilization of more than 3700 years and the largest distribution center of Chinese herbal medicine in China. It is listed in the first batch of strategic emerging industrial agglomeration and development base in Anhui Province.

- Talent advantage: With a well-designed ability selection and appointment mechanism, the company actively seeks and attracts a large number of competent, interested and professional people to enter the company according to its own human resources planning and actual employment needs.

\subsection{Weaknesses}

- It is difficult to introduce high-end talents due to its poor geographical location: Because the company is located in Bozhou City, Anhui Province, the economic development is relatively backward, the geographical location is not good, it is difficult to introduce high-end talents. Due to the inconvenience of transportation, the transportation cost is higher, and it is generally at a disadvantage compared with developed areas and coastal cities.

- Limited financing means and hindered scale development: Traditional Chinese medicine products are a capital-intensive industry (Wei, 2018) which requires a large amount of capital to be invested in production and operation. However, due to the limitation of the company's size and position in the industry, it is mainly financed by shareholders' investment and bank loans at 
present, and the financing means are very limited, which hinders the company's scale development.

- The treatment course of traditional Chinese medicine is slow and the treatment cycle is prolonged: With the acceleration of people's pace of life, more and more medical consumers are pursuing faster treatment and shorter treatment cycle. Compared with western medicine, traditional Chinese medicine has fewer side effects as soon as possible. However, choosing traditional Chinese medicine will cost consumers more time, which is also an important reason why many people choose western medicine.

\subsection{Opportunities}

- The market demand of TCM is increasing rapidly: First of all, residents' awareness of health and health has been strengthened with the reform of the medical and health system. Secondly, during the anti-epidemic period, the demand of traditional Chinese medicine represented by Lianhua Qingwen Capsules soared in the domestic and international markets, and the related secondary market share price rose in the lead.

- Industrial development is highly valued: At present, TCM has the characteristics of "whole industrial chain" through the primary, secondary and tertiary industries, and has become a new hot spot of China's economic growth. According to Chinese customs statistics, China's total drug exports reached $\$ 3.909$ billion in 2018. According to the World Health Organization, four billion people around the world are now treated with medicinal plants. With the support of national policies, local governments have also shown great love to the TCM industry and introduced local policies to promote its development. Anhui, Gansu, Henan and other provinces have all set the goal of building TCM into a strong province and incorporating TCM development into their local economic and social development plans.

\subsection{Threats}

- The threat of increased regulation in the pharmaceutical industry: The pharmaceutical industry is part of the concession industry, and the implementation of the new medical policy, including the improvement of the essential medicine system, the implementation of the new GSP, GMP medicines, and the revision, improvement and implementation of the legal system, such as the Drug Administration Law, will accelerate the standardization of the pharmaceutical industry in China.

- Low efficiency of resource production and development: Due to the insufficient development and comprehensive utilization of the abundant Chinese herbal medicine resources in China, the large consumption of natural resources has almost exhausted some valuable Chinese herbal medicine resources. The research of medical cultivation technology has not been fully developed, the production and quality management of medical products in 
China are extensive, and the phenomenon of low yield and poor quality is more common.

- The threat of inadequate external environment: Although there is great potential for the development of TCM, the external environment for the development of TCM is not favorable enough. The development of TCM has been accelerated in economically developed and less developed areas. However, the development of TCM in many parts of central China is not obvious.

\section{Financial Index and Valuation Analysis of the Company to Be Listed}

\subsection{Analysis of Major Financial Indicators}

\subsubsection{Solvency Analysis}

Current ratio $=\frac{(\text { Current assets })}{(\text { Current liabilities })}$, the higher the current ratio, the stronger the solvency of the enterprise (Weng, 2018). But the ratio cannot be too high, the ratio is better controlled at about 2. As can be seen from the data in Table 3, although the flow ratio in the recent three years first dropped and then rose, it basically maintained between 2 - 3. It shows that the enterprise has strong solvency and asset utilization ability.

The multiple of interest safeguard $=\frac{(\text { Profit before interest and tax })}{\text { (Interest charges })}$, the higher the value, the stronger the ability to pay interest. The company's interest guarantee multiple varies between 5 and 10, indicating that the company has less pressure to repay the interest and has less investment risk.

Asset-liability ratio $=\frac{(\text { The total amount of liabilities })}{(\text { Total assets })}$, The ratio of assets to liabilities can be used to reflect the operating risks of an enterprise. The ratio of assets to liabilities of Company Y has been maintained at about 30\% in the past three years. Compared with liabilities, assets account for a larger proportion, indicating that there is enough capital to cover liabilities and that the company has certain capital utilization capacity.

Based on the above analysis, it can be seen that the company develops steadily, its financial position and asset liquidity are relatively stable, the cash flow generated from business activities is abundant, its credit standing is good, and its solvency is also strong.

Table 3. Solvency index statistics.

\begin{tabular}{cccc}
\hline Project/Year & 2017 & $\mathbf{2 0 1 8}$ & $\mathbf{2 0 1 9}$ \\
\hline Liquidity Ratio (times) & 3.19 & 2.59 & 3.15 \\
The multiple of interest safeguard & 9.59 & 5.84 & 5.94 \\
Asset-liability ratio & $30.78 \%$ & $38.04 \%$ & $30.5 \%$ \\
\hline
\end{tabular}




\subsubsection{Operational Capacity Analysis}

Accounts receivable turnover $=\frac{\text { (Operating income) }}{\text { Average balance of accounts receivable }}$, The

company's accounts receivable turnover was 2.79 times in 2017, 1.38 times in 2018, and 1.79 times in 2019. The accounts receivable turnover showed a trend of first decline and then rise, and remained at about 2, indicating that the enterprise's accounts receivable risk is very small and the credit risk is relatively low (Xia, 2020).

$$
\text { Inventory turnover }=\frac{\text { (Operating cost })}{\text { Average balance of inventory }}, \text { Inventory turnover is used }
$$

to measure the inventory level of an enterprise. In other words, inventory turnover $=$ sales revenue/inventory. The greater the demand for products, the better the sales status of the enterprise, the faster the product turnover, large sales can be achieved through less inventory, the higher the inventory turnover rate; On the contrary, when the sales situation of the enterprise is poor, the slower the product turnover, the lower the inventory turnover. As can be seen from Table 4 , the inventory turnover of the company declined in 2018, but recovered slightly in 2019, and generally maintained at a normal level.

Generally speaking, the company has a low risk of accounts receivable and a low credit risk. There is no situation of inventory accumulation and poor turnover, and the overall operating capacity is good.

\subsubsection{Profitability Analysis}

There are many indicators to evaluate the profitability of an enterprise. The following three indicators are selected to analyze the profitability of an enterprise.

The growth rate of total operating income is a reflection of the operating conditions of an enterprise in a fiscal year. It can be seen that the growth rate of operating income in 2017 and 2019 is as high as $17.19 \%$ and $26.30 \%$ respectively, mainly because the company expanded the production scale in this year and the operating income increased accordingly (Yan, 2018). The growth rate of operating income decreased in 2018, mainly because the company did not carry out business in the former local pharmaceutical companies and small hospitals (below Grade A three hospitals) in 2018, because these hospitals had high risks. Therefore, the company has decisively terminated this business for the long-term development of the company. Generally speaking, the growth rate of operating income is positive when there is no major change, and the operating income in 2017 and 2019 is increasing continuously, indicating that the business is in good condition.

Table 4. Operation capacity index statistics.

\begin{tabular}{cccc}
\hline Project/Year & 2017 & $\mathbf{2 0 1 8}$ & 2019 \\
\hline Accounts receivable turnover rate (times) & 2.79 & 1.38 & 1.79 \\
Inventory turnover rate (times) & 14.03 & 1.99 & 2.07 \\
\hline
\end{tabular}


INet asset per share $=\frac{(\text { Year-end shareholders' equity })}{(\text { Total common stock at year-end })}$, the higher the index, the greater the wealth per share. As can be seen from the data in Table 5, the highest value in 2019 is 3.25, and it has been on the rise in recent three years, indicating that enterprises have strong ability to create profits and resist the influence of external factors.

Basic earnings per share

(Current net profit attributable to ordinary shareholders)

$=\overline{\text { (The weighted average of the number of common shares outstanding during the period) }}$

It reflects the ability of common shareholders to earn profits from shares held by them. The higher this index is, the stronger the company's profitability is. Observing the above table, the basic earnings per share show a downward trend, indicating that the profitability of the enterprise has declined.

In general, the company has a good annual income, strong ability to create profits and good profitability.

\subsubsection{Growth Ability Analysis}

The trend of growth ability index is shown in Figure 2.

As can be seen from Table 6 and Figure 2, the growth rate of total assets

Table 5. Statistics of profitability indicators.

\begin{tabular}{cccc}
\hline Project/Year & 2017 & $\mathbf{2 0 1 8}$ & $\mathbf{2 0 1 9}$ \\
\hline Year-on-year growth rate of total operating revenue & $17.19 \%$ & $-56.91 \%$ & $26.30 \%$ \\
Net asset per share & 2.62 & 2.94 & 3.25 \\
Basic earnings per share & 0.62 & 0.32 & 0.30 \\
\hline
\end{tabular}

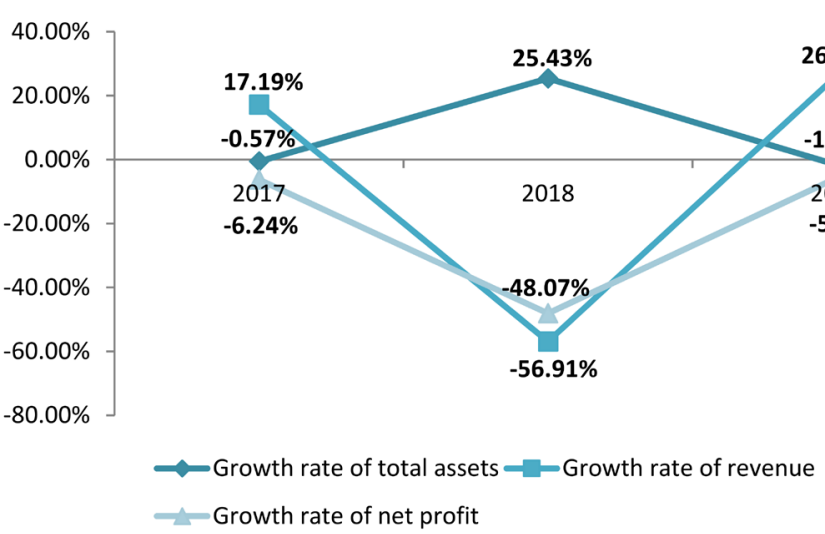

Figure 2. Growth capacity index line chart.

Table 6. Growth ability index statistics.

\begin{tabular}{cccc}
\hline Project/Year & 2017 & 2018 & 2019 \\
\hline Growth rate of total assets & $-0.57 \%$ & $25.43 \%$ & $-1.66 \%$ \\
Growth rate of revenue & $17.19 \%$ & $-56.91 \%$ & $26.30 \%$ \\
Growth rate of net profit & $-6.24 \%$ & $-48.07 \%$ & $-5.68 \%$ \\
\hline
\end{tabular}


showed a growth trend of first rising and then falling. Operating income declined a lot in 2018 and increased a lot in 2019 (Zhu, 2017). The change trend of net profit growth rate and operating income growth rate were roughly the same, but in general, these three indicators recovered to the normal level or even better in 2019 after the business changes in 2018, and the operating income was accelerating, indicating that the company had strong growth ability and good development prospect and potential.

\subsection{Valuation Analysis of Companies to Be Listed}

\subsubsection{Relative Valuations}

According to the industry classification of China Securities Regulatory Commission, the company belongs to the pharmaceutical manufacturing industry of Chinese medicinal materials and Chinese patent medicine processing industry $(\mathrm{Li}$, 2019). At present, there are many listed companies with the same main business as the target company in China's stock market. In this paper, five representative listed companies from the New Third Board are selected as comparable companies, namely: Changxing Pharmaceutical, Zhenghe Pharmaceutical, Kangyuantang, Datang Pharmaceutical and Tianji Caotang. Based on the closing price on May 15, 2020, the dynamic valuation of the above companies is carried out, and the forecast average value of EPS is taken from Wind statistics.

As can be seen from Table 7, the average PE of the five Chinese medicine pharmaceutical enterprises we selected is 23.44 , while the company's expected 2020 net earnings per share is 0.30 yuan, corresponding valuation level is 7.03. Since Company Y has developed steadily and is expanding steadily, has strong strength, good internal management and a high market share, which is in line with the national industrial policy, we will offer a certain premium, which is estimated to be about 7.1 yuan.

\subsubsection{Absolute Valuation}

The discount cash flow method is used to estimate the stock of the company (Shi, 2015). Specific assumptions and known quantities are shown in Table 8.

- Assume that the risk-free interest rate is $2.5 \%$.

Table 7. Dynamic valuation table.

\begin{tabular}{ccccccc}
\hline \multirow{2}{*}{ code } & name & Share price & \multicolumn{3}{c}{ EPS } & \multicolumn{2}{c}{ PE } \\
\cline { 5 - 7 } & & (yuan) & 2017 & 2018 & 2019 & 2020 \\
\hline 835269 & Changxing pharmaceutical & - & 0.46 & 0.58 & 0.78 & - \\
832257 & Zhenghe Pharmaceutical & 5.30 & 0.37 & 0.36 & 0.07 & 22.50 \\
873173 & Kang Yuantang & 5.50 & 0.18 & 0.52 & 0.46 & 23.01 \\
836433 & Datang Pharmaceutical & 7.01 & 0.51 & 0.38 & 0.51 & 24.32 \\
871129 & Tianji Thatched Cottage & 6.07 & 1.07 & 0.63 & 0.48 & 23.94 \\
Mean value & & - & - & - & - & 23.44 \\
\hline
\end{tabular}


- Assume that the return on equity of the company is the expected return rate of the market, that is, $6.21 \%$.

- The $\beta$ coefficient of the industry is 0.97 .According to the formula: cost of equity $=$ risk-free rate + beta $*$ (market expected rate of return - risk-free rate).That is, cost of equity $=2.5 \%+0.97 *(6.21 \%-2.5 \%)=6.10 \%$.

- It is assumed that the cost of debt is that the company obtains a one-year loan rate of $4.35 \%$.

- According to the company's financial statements, the debt ratio of the company is $30.49 \%$, so the equity ratio is 1 , the debt ratio, i.e. $69.51 \%$.

- The company's tax rate is $25 \%$.

Weighted Average Cost of Capital:

WACC $=$ Cost of Equity ${ }^{*}$ Equity Ratio + Cost of Debt ${ }^{*}$ Debt Ratio $(1-$ Tax Rate $)=6.10 \% * 69.51 \%+4.35 \% * 30.49 \% *(1 \%-25 \%)=5.23 \%$.

Assuming that the company's earnings per share grow at $1 \%$ perpetually, according to the perpetually growing dividend discount model, intrinsic value of the stock $=$ next year's net earnings per share/(WACC - sustainable growth rate).That is, the 2019 stock value of the company $=0.30 *(1 \%+1 \%) /(5.23 \%-$ $1 \%)=7.16(\mathrm{Li}, 2018)$.

When WACC and sustainable growth rate change, corporate value is shown in Table 9.

Table 8. Assumptions and known quantities.

Unit: \%

\begin{tabular}{cc}
\hline The index name & Ratio (\%) \\
\hline Risk-free rate & 2.5 \\
Market expected yield & 6.21 \\
Beta coefficient & 0.97 \\
Cost of debt & 4.35 \\
Debt ratios & 30.49 \\
Equity ratio & 69.51 \\
rate & 25 \\
\hline
\end{tabular}

Table 9. Sensitivity analysis of discounted cash flow model (DCF).

\begin{tabular}{cccccc}
\hline & \multicolumn{5}{c}{ Sustainable growth rate } \\
\cline { 2 - 5 } WACC\% & $\mathbf{0 . 5 \%}$ & $\mathbf{0 . 7 5 \%}$ & $1 \%$ & $\mathbf{1 . 2 5 \%}$ & $\mathbf{1 . 5 \%}$ \\
\hline $0.85 \%$ & 11.04 & 12.19 & 13.59 & 15.34 & 17.60 \\
$1.85 \%$ & 8.08 & 8.69 & 9.38 & 10.19 & 11.15 \\
$2.85 \%$ & 6.37 & 6.75 & 7.16 & 7.63 & 8.16 \\
$3.85 \%$ & 5.26 & 5.52 & 5.79 & 6.10 & 6.44 \\
$4.85 \%$ & 4.48 & 4.66 & 4.86 & 5.08 & 5.31 \\
\hline
\end{tabular}




\subsubsection{Absolute Valuation}

Based on the sensitivity analysis of relative valuation and discounted cash flow model (DCF), the reasonable range of the actual value of the company's stock in 2020 is 6.79 yuan to 10.15 yuan, and the $\mathrm{P} / \mathrm{E}$ ratio is 20 to 30 times.

\section{Analysis and Suggestions on Y Company's IPO Financing}

At present, Chinese traditional medicine industry is in the growth period, and the government has formulated a series of specific policies to support the development of Chinese traditional medicine enterprises (Luo, 2019). And the international market of traditional Chinese medicine is itself still in the stage of rapid expansion, so the market potential of Chinese medicine, the whole traditional Chinese medicine industry development prospects are good.

At present, the target company is in a period of rapid development, with expanded business scale and higher requirements on scientific research and technology. Meanwhile, other expenditures are increased correspondently, and the net cash outflow from business activities is large. Therefore, the target company is in urgent need of listing for financing (Zhang, 2018). After the listing on the New Third Board, the financing cost is not only low, but also conducive to building the brand image of the company.

Through the analysis of the target company's historical data, its revenue and profit have been increasing year by year, and its profitability is strong. It is predicted that its profitability will still have a large room for improvement in the future. Company Y focuses on the development and sales of TCM decoction pieces, with strong core competitiveness. Through the comparison and analysis of the information disclosed by a number of listed traditional Chinese medicine enterprises on the New Third Board (NEEQ), their profitability, operating income and other indicators have ranked the top of the traditional Chinese medicine enterprises on the NEEQ since their listing, and the quality of the companies is high.

The target company meets the requirements for listing on the New Third Board in terms of legal standards, business existence, personnel setup, financial indicators, etc.

To sum up, combining absolute valuation and relative valuation, this paper believes that the target company is fully capable of listing on the New Third Board and qualified for the market requirements. The listing price is around 7 yuan and the PE ratio is about 25 times.

\section{Conflicts of Interest}

The author declares no conflicts of interest regarding the publication of this paper.

\section{References}

Li, C. (2018). Comparative Analysis of EVA Valuation Method and DCF Valuation Me- 
thod. Beijing: University of International Business and Economics.

Li, Y. N. (2019). Study on the Applicability of Value Evaluation Methods for Listed Companies in Traditional Chinese Medicine Industry. Shanghai: Donghua University.

Luo, H. (2019). Feasibility Analysis and Countermeasure Study of FR Company Listed on New Third Board. Xi'an: Xidian University.

Shi, H. (2015). Research on Valuation of Listed Companies in Chinese Traditional Chinese Medicine Manufacturing Sector. Shanghai: Shanghai Jiao Tong University.

Wei, G. N. (2018). Feasibility Analysis of Dual Share System in China Based on SWOT Analysis: A Case Study of Jingdong's Listing in the United States. Accounting for Township Enterprises in China, No. 10, 27-28.

Weng, Q. S. (2018). Analysis of the Listing Feasibility of Anhui City Pharmaceutical Co., Ltd. Based on Financial Indicators. Economic and Trade Practice, No. 16, 57+59.

Xia, M. L. (2020). Analysis on Financial Performance Evaluation of Yiling Pharmaceutical Company. Shanghai Commerce, No. 4, 58-59.

Yan, C. X. (2018). Research on the Proitability Model and Financial Evaluation of $X$ Company. Shenyang: Shenyang University,.

Zhang, S. K., \& Yuan, L. J. (2018). Research on the Feasibility of Listing of Enterprises Based on Financial Analysis: A Case Study of Anhui Airite. Public Investment Guide, No. 24, 220-221.

Zhu, X. J. (2017). Research on Financial Risks of Listed Companies in Traditional Chinese Medicine Industry. Chengdu: Southwest Jiaotong University. 